\title{
Research and Analysis of concrete facilities' corrosion in coastal substaion of fujian
}

\author{
Yang Dishan ${ }^{1}$, Zhang Jinbo ${ }^{1}$, LIN Xi ${ }^{1}$, Huang HuanXin ${ }^{2}$ \\ ${ }^{1}$ National Grid Fujian Electric Power Co., Ltd. Institute of Economics and Technology, Fuzhou 350012, China \\ ${ }^{2}$ Power China Fujian Electric Power Engineering Co., Ltd., Fuzhou 350001, China
}

\begin{abstract}
Corrosion problems of outdoor concrete facilities was summarized through research on coastal substation of Fujian, such as serious corrosion of steel ring and weld in the joints of cement poles, exposure and corrosion of reinforcement, cracking and falling off of concrete cover. The information of concrete facilities' assessment reports was summarized, and it was found that concrete compressive strength of present age satisfied early design drawings. In addition, appraisal of reliability revealed that all facilities couldn't satisfy the requirements of current standards and seismic appraisal revealed that all facilities couldn't meet the seismic requirements. The analysis of concrete facilities' corrosion mechanism was made, and it was found that concrete facilities in coastal substation suffered triple effects of carbonation, chloride corrosion and stray current corrosion. The power failure schemes needed for present repairing and strengthening measures of concrete facilities lack of feasibility. Research on repairing and strengthening measures of concrete facilities that requiring no or small-scale power cut would be of great significance.
\end{abstract}

\section{Introduction}

Fujian outdoor substation frame has concrete frame and steel frame two schemes. With the improvement of economic level, the frame constructed after 2006 generally adopts steel frame, while the frame constructed before this is all concrete frame. The concrete truss column is generally made of precast annular cement pole, with longitudinal bars and spiral stirrups, and the truss beam is Angle triangular lattice beam. In recent years, with the increase of the renovation and expansion projects of old substations that have been in operation for more than 20 years, it has been found that the concrete frame columns of these old stations have serious corrosion problems, and the mechanical properties of the frame columns are not enough to support the power grid renovation plan, or even to guarantee the safety under the current operating conditions. In order to ensure the safe operation of the whole power grid, it is urgent to investigate and analyze the corrosion of the concrete frame of the substation.

\section{Investigation of corrosion conditions}

\subsection{Category of Corrosion Problems}

Time of Fujian province was put into operation for more than 20 years old substation site investigation found that the old station common concrete frame column in the steel and concrete pole joint weld serious rust, steel rust, concrete cover exposed burst off visible corrosion problems, these problems have seriously affect the structure reliability and safety.

The concrete truss column is assembled by butt welding of the steel ring of the rod head of the precast annular cement rod. The steel ring is the key force transfer joint of the concrete truss column. The steel ring and the weld seam are seriously corroded (Figure 1), which weakens the stressed area of the cross section at the joint and reduces the bearing capacity of the truss column. Prefabricated circular concrete pole configuration of longitudinal reinforcement and spiral stirrups to improve the bearing capacity of normal section and inclined section, section bar shaft cover off cause longitudinal reinforcement and stirrup the leakage and corrosion (Figure 2), weakened the reinforcement stress area, and rust particles can also cause the burst loss of concrete protective layer, forming " rebar corrosion steel corrosion protection layer burst loss -" the vicious circle. The on-site survey of the substation found that the concrete protective layer fell off the body of most cement poles (Figure. 3). This part of the bar is in the early stage of corrosion development, if left untreated, it will lead to the exposure of reinforcement and further corrosion, and the lack of protective layer will also cause adverse effects on the stability of longitudinal bars. The above-mentioned multiple problems often occur at the same time in a single cement pole. For example, the exposed steel bar means that the concrete protective layer has fallen off. Some rods are even found in the same place with serious corrosion of steel ring and weld seam and exposed steel bar (Figure. 4),

\footnotetext{
* Corresponding author: 550818454@qq.com
} 
causing great hidden danger to the safe operation of the substation.

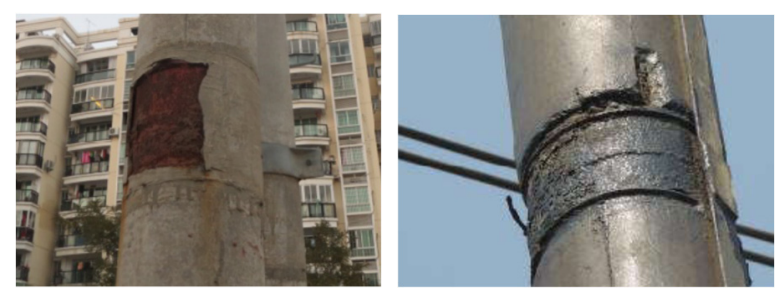

Figure 1. Serious corrosion of steel ring and welding seam
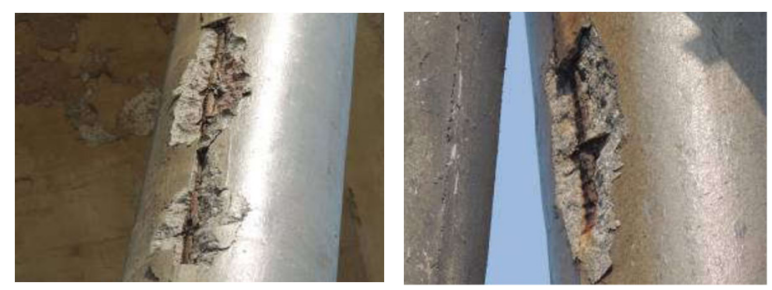

Figure 2. exposed corrosion of steel bar
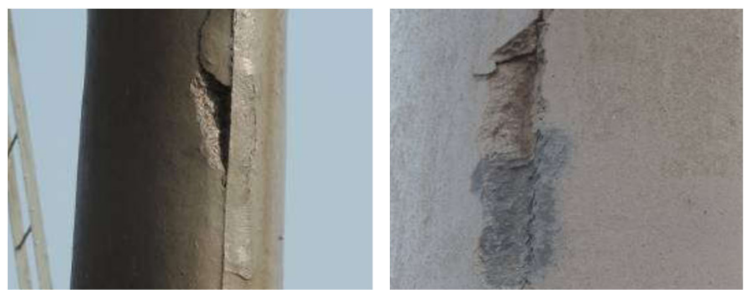

Figure 3. Concrete protective layer bulges, cracks and falls off
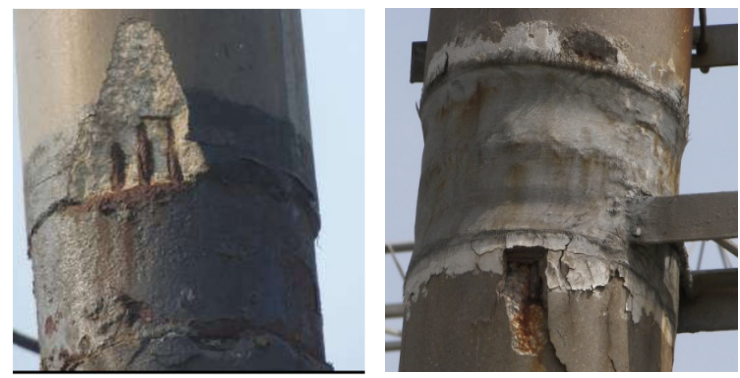

Figure 4. Triple corrosion coupling

\subsection{Structural assessment of corroded concrete frames}

The power company entrusted the professional testing center to carry out structural evaluation on the concrete frames of $220 \mathrm{kV}$ and $110 \mathrm{kV}$ substation that have been put into operation for more than 20 years. The evaluation contents include the use of rebound method to test the compressive strength of the concrete frame columns at present age, and the reliability evaluation and seismic performance evaluation of the frame based on the field survey results.

According to a total of 34 evaluation reports of the frame, the compressive strength of the concrete in the current age of the frame columns can all meet the requirements of the early design drawings, indicating that concrete carbonization does not directly affect the performance of concrete. The field survey results show that all the frames have the phenomenon of exposed corrosion of cement rod and steel ring. For example, in a
$220 \mathrm{kV}$ frame in Quanzhou, the steel ring at the connection of cement pole of concrete frame column is generally corroded. The rod body generally has different degrees of exposed corrosion of steel bar and bulging and cracking of concrete protective layer. According to the "Industrial Building Reliability Evaluation Standard" [1], the testing center carries out reliability evaluation on 34 frames, among which 29 frames are rated as Level 4, that is, they do not meet the safety requirements of the current national standards, and have seriously affected the safe operation of the substation, and must take immediate measures; The reliability level of the five frameworks is rated as Level 3, that is, they do not meet the safety requirements of the current national standards and affect the safety, and measures should be taken; According to the Seismic Evaluation Standard for Structures [2], the seismic performance of 34 frames was evaluated, and none of the frames met the seismic requirements.

The evaluation report of the concrete frame reflects the risk of the transformer substation frame which has been in service for more than 20 years. All the frames do not meet the safety requirements of the current national standards. Measures should be taken to solve the corrosion problem of the concrete frame of the old station.

\section{Analysis of corrosion mechanism of concrete cement pole}

In general atmospheric environment, concrete carbonation is the main reason for the corrosion of concrete cement pole and steel bar. For the concrete frame column in the coastal substation, it is simultaneously subjected to the triple coupling effect of concrete carbonation, chloride ion corrosion and stray current corrosion.

\subsection{Carbonization of concrete}

Cement produces a large amount of calcium hydroxide in the hydration process, and the pore water of concrete is calcium hydroxide saturated solution with a $\mathrm{pH}$ value of about $12 \sim 13$, showing strong alkalinity ${ }^{[3 \sim 5]}$. Due to the existence of high alkalinity concrete hole solution, the concrete concrete surface formed a stable and compact passivation film, has a good protective effect on the reinforcement. Carbon dioxide in the atmosphere diffuses through the pores of concrete to its interior, and reacts with calcium hydroxide to produce calcium carbonate, which is the carbonization of concrete. The reaction formula is as follows:

$$
\mathrm{Ca}(\mathrm{OH})_{2}+\mathrm{CO}_{2} \rightarrow \mathrm{CaCO}_{3}+\mathrm{H}_{2} \mathrm{O}
$$

The occurrence of concrete carbonization does not directly affect concrete, but generates $\mathrm{CaCO}_{3}$ to reduce its $\mathrm{pH}$ value, which causes the destruction of the passivation film on the surface of the steel bar, so that $\mathrm{O}_{2}$ in the air can directly contact the steel bar and oxygen absorption corrosion occurs. The chemical reaction formula is as follows:

$$
\mathrm{Fe}+\mathrm{O}_{2}+\mathrm{H}_{2} \mathrm{O} \rightarrow \mathrm{Fe}(\mathrm{OH})_{2}
$$

$\mathrm{Fe}(\mathrm{OH}) 2$ will be further oxidized to $\mathrm{Fe}(\mathrm{OH}) 3$, dehydration to form loose, porous red rust $\mathrm{Fe} 2 \mathrm{O} 3$, under 
the condition of less oxygen, $\mathrm{Fe}(\mathrm{OH}) 2$ oxidation is not complete to form black rust $\mathrm{Fe} 3 \mathrm{O} 4$, the final corrosion products depend on whether oxygen is sufficient. The volume of rust is generally about 2.5 times that of iron. The pressure caused by the increase in volume makes the concrete protective layer bulge and crack, which further increases the contact between the steel bar and the outside world and intensifies the corrosion process of the steel bar. This vicious circle causes the damage of the corrosion of the steel bar to spiral out of control. Studies show that ${ }^{[6]}$, when the $\mathrm{pH}$ of concrete pore fluid is 9.88, the reinforcement surface begins to form passivating film, and when the $\mathrm{pH}$ value reaches 11.5 , the reinforcement surface forms a complete passivating film. The carbonation of concrete can reduce its $\mathrm{pH}$ value to below 9 and completely destroy the passivation film on the surface of the steel bar. It can be said that the carbonation of concrete is a prerequisite for the corrosion of the steel bar in the general atmospheric environment.

\subsection{Chloride ion corrosion in salt spray environment}

The concentration of chloride ion has an important relationship with the type of environment, and the concentration of chloride ion is higher in coastal areas. The existing concrete structure durability evaluation standard "[7] the chloride ion erosion environment can be divided into coastal atmospheric environment, atmosphere salt fog area and the change of water level area, splash zone, including offshore atmospheric environment is set to coast $0 \sim 1000 \mathrm{~m}$, studies have shown that ${ }^{[8]}$, salt fog environment chloride ion corrosion of concrete damage and even more serious than the seawater erosion.

The corrosion mechanism of chloride ion has two aspects: the destruction of passivation film and the electrochemical reaction of corrosion. Studies show that [9 11], when the chloride ion content on the surface of steel bars in concrete reaches a certain concentration, the passivation film on the surface will begin to destroy, and then lead to corrosion of steel bars. The destruction mechanism of chloride ions on the passivation film is consistent with that of carbonization. The chemical reaction between chloride ions and calcium hydroxide solution reduces the $\mathrm{PH}$ value of concrete hole solution, leading to the destruction of the passivation film and corrosion ${ }^{[12 \sim 17]}$. After the destruction of the passivation film, an electrochemical corrosion reaction occurs between chloride ions and the exposed cationic $\mathrm{Fe} 2+$ in the iron matrix, and the reaction formula is as follows:

$$
\mathrm{Fe}^{2+}+\mathrm{Cl}^{-}+\mathrm{H}_{2} \mathrm{O} \rightarrow \mathrm{Fe}(\mathrm{OH})_{2}+2 \mathrm{HCl}
$$

From the corrosion mechanism analysis, chloride ions in the corrosion process as a catalyst, all into the concrete chloride ions, will play a destructive role over and over again. Studies have shown that ${ }^{[18]}$, the corrosion rate of chloride ion on reinforcement is generally faster in the early stage, and decreases with the increase of corrosion products. When the internal structure of concrete is damaged, the corrosion rate will accelerate again. In addition to the destruction of the passivation film and catalytic electrochemical corrosion, chloride ion can also directly with the concrete in the $\mathrm{Ca}(\mathrm{OH})_{2}, 3 \mathrm{CaO} \cdot \mathrm{Al}_{2} \mathrm{O}_{3} \cdot$ $6 \mathrm{H}_{2} \mathrm{O}$ to form a much larger volume than the reactants of solid compounds, so that the concrete expansion crack.

\subsection{Stray current corrosion}

The current that is not transmitted according to the original set path is called stray current, and the corrosion caused by it is called stray current corrosion. In recent years, many scholars devoted to stray current corrosion effects of metro and light rail research think stray current corrosion on track than fatigue durability damage, chloride ion corrosion is more serious ${ }^{[20]}$, ministry of organization compiled the "metro stray current corrosion protection technology standard" [21], specific measures to improve the subway stray current protection design and the technical level. Current transformer substation stray current corrosion in concrete frame has not yet been taken seriously, jian-yu Yang, etc. ${ }^{[22]}$ study, stray current through concrete structure, under the conductive effect of reinforcement, current be brought into the drainage points, steel cathode area change current strength, current to achieve a certain strength, reinforced surface cathodic hydrogen evolution reaction, The hydrogen precipitated in the member inside the formation of pressure, so that the steel bar and concrete off, and the concrete protective layer expansion crack; In the anode part of reinforcement, the passing of stray current will accelerate the transport of ions, accelerate the occurrence of oxidation process, and promote the corrosion and expansion of reinforcement. The corrosion of rebar caused by stray current is essentially the same as the electrochemical corrosion caused by chloride ions, but the stray current is tens or even thousands of times larger than the electrochemical corrosion current caused by chloride ions numerically ${ }^{[23]}$.

The concrete framework of substations built in coastal areas is corroded by the coupling of chloride ion and stray current at the same time. Studies show that when chloride ion coexists with stray current, chloride ion intensifies the stray current corrosion [24]. The limit concentration, existence form and migration rate of chloride ions that induce steel corrosion are also affected by stray current ${ }^{25-}$ ${ }^{26]}$. According to the study of Chen Xunjie et al. ${ }^{[27]}$, the concentration of chloride ion in concrete increases with the increase of stray current density and erosion age in the chloride salt-stray current environment.

\section{Analysis of reinforcement measures for concrete cement pole repair}

\subsection{Research progress on repair and reinforcement measures of cement poles}

The existing repair and reinforcement measures for cement poles include those aimed at durability and those aimed at safety. The corrosion of concrete frame columns in substations is serious, and neither of the above two measures is necessary. Technical Specification for Durability Repair and Protection of Concrete Structures ${ }^{[28]}$ puts forward guidance schemes for various durability 
problems. For various reinforcement corrosion, repair measures such as reinforcement rust resistance treatment, electrochemical re-alkalization, electrochemical desalination and cathodic protection can be adopted. For various cracks, repair methods can be divided into surface treatment method, filling sealing method, pressure grouting method; Concrete surface repair materials can be used interface treatment materials and repair mortar, surface protection materials can be used inorganic materials, organic polymer materials and composite materials. The Code for Design of Reinforcement of Concrete Structures ${ }^{[29]}$ puts forward guidance schemes for various safety problems, which can be used to increase the bearing capacity of members, such as the reinforcement method of increasing section, the reinforcement method of outer section steel, the reinforcement method of bonded steel plate, and the reinforcement method of bonded fiber composite material. In recent years, studies on the repair and reinforcement of substation concrete frame columns ${ }^{[30-33]}$ have mostly started from the above two aspects, and the repair and reinforcement measures have not been separated from the standard methods. Some scholars have done some studies from the perspective of new grouting materials and new reinforcement materials ${ }^{[34-35]}$, and some scholars have proposed a scheme of overall replacement of the frame ${ }^{[36]}$.

\subsection{Difficulties in repair and reinforcement of cement pole}

The existing research on the repair and reinforcement measures of concrete frame columns in substations has ignored a difficult point: the feasibility of power outage scheme. In general, the safety distance of the side of the $110 \mathrm{kV}$ frame column is $1.65 \mathrm{~m}$, and the safety distance of the side of the $220 \mathrm{kV}$ frame column is $2.55 \mathrm{~m}^{[37]}$. During the construction period, no material or even the flying sparks or water spray is allowed to enter the electrified area, otherwise the air will be broken down by the high pressure and a major safety accident will occur. Existing framework column reinforcement plans need to build 10$20 \mathrm{~m}$ high scaffolding, but also need to operate a variety of construction tools, it is impossible to avoid multi-interval power failure at the same time, the establishment of power failure plan is the existing substation concrete frame column reinforcement of the biggest difficulty. In the preparation of transformation plans for $220 \mathrm{kV}$ substations in Xiamen, Quanzhou and Putian, due to the difficulty in coordinating power failure plans with framework reinforcement and lack of constructibility, the total station reconstruction combined with the intermediate transition plan was finally chosen, resulting in a ten-fold increase in investment. The corrosion problem of the concrete frame of the old station has become increasingly prominent. The repair and reinforcement scheme without power failure or with small power failure scale will bring huge economic benefits and is of great significance.

\section{5 conclusion}

According to the investigation results of substations in coastal areas of Fujian Province that have been in operation for more than 20 years, there are widespread corrosion problems in concrete frame columns, such as severe corrosion of steel ring and weld at the connection of cement pole, exposed corrosion of steel bar, swelling, cracking and shedding of concrete protective layer. From the frame reliability evaluation report, these frames do not meet the safety requirements of the current national standards, do not meet the seismic requirements, the solution of concrete frame column corrosion problem has been imminent. Concrete carbonation, chloride ion corrosion in salt spray environment and stray current corrosion are the three major reasons for severe corrosion of concrete frame columns in coastal substations. Combined with the analysis of engineering experience, the existing repair and reinforcement measures of concrete frame columns require power failure schemes with low feasibility, and the study of repair and reinforcement schemes without power failure or with small power failure scale is of great significance.

\section{References}

1. Ministry of Housing and Urban-Rural Development of the People 's Republic of China.Industrial Building Reliability Appraisal Standard : GB 50144-2019 [S].Beijing : China Construction Industry Press, (2019).

2. Ministry of Housing and Urban and Rural Construction of the People ' $\mathrm{s}$ Republic of China.Structure seismic appraisal standard : GB 50117-2014 [S].Beijing : China Construction Industry Press, (2014).

3. Xiao Jia,GOU Cheng-fu. Overview of the research for concrete carbonation[J]. Concrete, 01 (2010): 40$44,52$.

4. Xiao Weiwei, Zhang Jigang, Zhang Junbo, et al . Research review on concrete deterioration under the combined action of carbonation and chloride[J]. china concrete and cement products, 12 (2019): 24-28.

5. Wang Jianhua, Wang Zuhe, Mu Zhengao.Concrete steel corrosion and rust inhibitor use [J].Shanxi architecture, 36,27 (2010): 54-55.

6. Hong naifeng. Concrete alkalinity and steel corrosion [J]. Concrete and cement products, 5 (1990): 16-18.

7. Ministry of Housing and Urban-Rural Development of the People 's Republic of China. Durability assessment criteria for existing concrete structures : GB / T 51335-2019 [S]. Beijing : China Construction Industry Press, (2019).

8. Wu Qingling, Yang Yihong, Fei Weiwei.Deterioration damage of concrete in salt spray corrosion and seawater erosion [ $\mathrm{J}$ ].Concrete and cement products, 11 (2014): 30-34. 
9. Poursaee A. Temperature dependence of the formation of the passivation layer on carbon steel in high alkaline environment of concrete pore solution[J]. Electrochemistry Communications, $\mathbf{7 3}$ (2016): 24-28.

10. Scott A, Alexander M G. Effect of supplementary cementitious materials (binder type) on the pore solution chemistry and the corrosion of steel in alkaline environments $[\mathrm{J}]$. Cement \& Concrete Research, 89 (2016): 45-55.

11. Yao Senyuan, Yan Jiali, Liu Junzhe, etc.Research on the critical chloride ion concentration of steel bar in concrete [J]. Journal of NingBo university (NESS ) ,31,03 (2018): 83-88.

12. WANG Y, NANUKUTTAN S, BAI Y, et al. Influence of combined carbonation and chloride ingress regimes on rate of ingress and redistribution of chlorides in concretes[J]. Construction and Building Materials, 140 (2017): 173-183.

13. G. Roventi, T. Bellezze, E. Barbaresi, et al. Effect of carbonation process on the passivating products of zinc in $\mathrm{Ca}(\mathrm{OH}) 2$ saturated solution. 64,11 (2013): 1007-1014.

14. Jon Williamson, O. Burkan Isgor. The effect of simulated concrete pore solution composition and chlorides on the electronic properties of passive films on carbon steel rebar, 106 (2016): 82-95.

15. WU Qun, LIU Yu,,DU Ronggui, LIN Changjian. Electrochemical study on the passivation effect of chloride ion on reinforcement in simulated concrete pore solution[J]. Acta Metallurgica Sinica, 03 (2008): 346-350.

16. H. Burak Gunay, Pouria Ghods, O. Burkan Isgor, et al. Characterization of atomic structure of oxide films on carbon steel in simulated concrete pore solutions using EELS. 274(2013) : 195-202.

17. Li Xiaozhen, Liu Junzhe, Yan Jiali, etc. Effect of carbonation and chloride on steel bar passivation in concrete pore solution [J]. Journal of Building Materials, 23, 01(2020): 224-229.

18. He Yong, Tang Xianxi, Sun Shuhu, etc. Experimental study on corrosion resistance of bridge reinforced concrete based on electrochemical corrosion [J]. Concrete and cement products, 9 (2018): 10-15.

19. F.C. Robles Hernández, G. Plascencia, Kevin Koch. Rail base corrosion problem for North American transit systems[J]. Engineering Failure Analysis, 16, 1(2009):281-294.

20. Du Yingji, Ma Shaojun, Cai Yuebo, etc. Prediction of durability of concrete against stray current in subway engineering $[\mathrm{J}]$. Journal of Water Conservancy and Construction Engineering, 01 (2003): 7-9.

21. Ministry of Housing and Urban-Rural Development of the People ' s Republic of China.Technical standard for stray current corrosion protection of subway :
CJJT49-2020 [S].Beijing : China Construction Industry Press, (2020).

22. Yang Jianyu, Yi Weijian, Li Wensheng.Spurious current corrosion of reinforced concrete frame in substation [C]//Papers of the 2018 National Academic Annual Conference of Industrial Buildings ( Volume ) in Beijing, 48 (2018): 277-281.

23. Introduction to durability of concrete structures [ M ]. Shanghai : Shanghai Science and Technology Press,(2003).

24. Luca Bertolini, Maddalena Carsana, Pietro Pedeferri. Corrosion behaviour of steel in concrete in the presence of stray current.49, 3(2006): 1056-1068.

25. Wu Xiong. Study on the deterioration characteristics of concrete under the combined action of stray current and chloride ion [D]. Wuhan : Wuhan University of Technology, (2008).

26. Geng Jian. Study on the degradation mechanism of concrete in the environment of stray current and chloride ion [D]. Wuhan : Wuhan University of Technology, (2008).

27. Chen Xunjie, Ouyang Youngling, Qian Wenxun, etc. Influence of stray current on concrete corrosion in different environments [J]. Journal of Water Conservancy and Water Transport Engineering, 02(2014): 33-37.

28. Ministry of Housing and Urban and Rural Construction of the People' $s$ Republic of China.Durability Repair and Protection Technical Specification for Concrete Structures : JGJ / T 2592012 [S].Beijing : China Construction Industry Press, (2012).

29. Ministry of Housing, Urban and Rural Construction of the People 's Republic of China. Code for Design of Concrete Structure Reinforcement:GB 50367-2013 [S]. Beijing : China Construction Industry Press, (2013).

30. Liang Jingming, Li Xinhai, Zeng Lingcheng, etc. Research on Reinforcement Technology of Concrete Frame for Substation Equipment [J]. Electrical Technology, 21(2019): 115-117.

31. Xiang Mingrong. Study on basic mechanical properties and long-term mechanical properties of outdoor support for substation reinforced by fiber reinforced composite materials [J]. Southern energy construction, 2, S1(2015): 88-92.

32. Zou Chongxian. Study on Corrosion Mechanism and Anticorrosion Reinforcement Measures of Outdoor Brackets in Substations [J]. Industrial Buildings, 11(2006): 111-114.

33. Dong Manling, Li Peishan, Chen Xinliang.Corrosion of concrete members in substation and its prevention [J].Journal of Shandong Agricultural University (Natural Science Edition), 03(2001): 323-326.

34. Luo yexiong. Reinforcement Analysis and Design of Concrete Structure Support in Substation [J]. 
Architectural Design Management, 31, 11(2014): 85-87.

35. Li Wensheng, Chen Shizhi, Nie Ming, etc. Research on Reinforcement Design of Old Concrete Frame in Substation [J].Guangdong Electric Power, 29, 9(2016).

36. Peng Lijuan. Structural support reinforcement of 220 $\mathrm{kV}$ substation [ J ]. Rural electrification, $\mathbf{0 3}$ (2015): 12-14.

37. National Energy Bureau.Design specification of high voltage distribution equipment : DL / T 5352-2018 [ S ].Beijing : China Plan Press, (2018). 